\title{
A escola indígena intercultural: espaço/tempo de afirmação da identidade étnica e de desconstrução da matriz colonial ${ }^{1}$
}

\author{
Intercultural indigenous school: space/time of ethnic identity affirmation and \\ deconstruction of the colonial matrix
L'école indigène interculturelle: espace/temps d'affirmation de l'identité ethnique et de déconstruction de la matrice coloniale
La escuela indigena intercultural: espacio/tiempo de afirmación de la identidad étnica y de desconstrucción de la matriz colonial

\author{
José Licínio Backes* \\ (backes@ucdb.br)
}

Recebido em 10/04/2013; revisado e aprovado em 30/07/2013; aceito em 15/10/2013

\begin{abstract}
Resumo: O artigo reflete sobre o processo da escolarização indígena e a luta dos povos indígenas, culminando com o reconhecimento ao direito de uma escola indígena, intercultural, específica e diferenciada. Mostra que essa luta continua, pois o fim do colonialismo não significou o fim da colonialidade. Evidencia, ainda, como as falas de acadêmicos indígenas, obtidas por meio de entrevistas semiestruturadas, se articulam com os teóricos da interculturalidade e da escola indígena.

Palavras-chave: Escola indígena. Colonialidade. Identidade.

Abstract: This paper reflects on the process of indigenous schooling and the fight by indigenous people to have their right to an indigenous, intercultural, specific, differentiated school acknowledged. It shows that such fight has not finished, as the end of colonialism does not mean the end of coloniality. The paper also evidences how indigenous students' speeches, obtained from semi-structured interviews, are articulated with theoretical studies addressing both interculturality and indigenous school.

Key words: Indigenous school. Coloniality. Identity.

Résumé: L'article se penche sur le processus de scolarisation et la lutte des peuples indigènes, aboutissant à la reconnaissance du droit d'une école indigène interculturelle, spécifique et différenciée, montrant que cette lutte se poursuit, parce que la fin du colonialisme n'a pas signifié la fin de la mentalité colonialiste. Cet article montre aussi comment le discours des universitaires autochtones, obtenus au moyen d'entrevues semi-structurées, est articulé avec les théoriciens de l' interculturalité et de l'école indigène.

Mots-clés: École indigène. Colonialisme. Identité.

Resumen: El artículo reflexiona sobre el proceso de la escolarización indígena y la lucha de los pueblos indígenas, culminando con el reconocimiento del derecho de una escuela indígena, intercultural, específica y diferenciada, mostrando que esa lucha continúa, pues el fin del colonialismo, no significó el fin de la colonialidad. Muestra también cómo se articulan las declaraciones de académicos indígenas, obtenidas por medio de entrevistas semiestructaradas, con los teóricos de la interculturalidad y de la escuela indígena.

Palabras clave: Escuela indígena. Colonialidad. Identidad.
\end{abstract}

\section{Introdução}

As últimas décadas no Brasil têm se caracterizado pela luta por uma escola que contemple a diversidade cultural, questionando a escola que apenas valoriza a cultura hegemônica. Nessa luta, os movimentos indígenas têm se destacado, construindo uma escola intercultural, específica e diferenciada, voltada para a valorização de sua cultura e a afirmação de suas identidades.

$\mathrm{O}$ presente artigo insere-se nesse contexto, refletindo sobre esse processo e argumentando que essa luta é protagonizada pelos próprios indígenas. Nas comunidades indígenas, a discussão sobre qual escola e com

\footnotetext{
* O artigo é fruto da pesquisa "A compreensão dos professores da educação básica sobre os processos de exclusão social atualmente presentes na sociedade brasileira e as relações com as suas concepções curriculares", financiada pelo $\mathrm{CNPq}$, na qual o autor deste artigo participa como pesquisador. Embora o roteiro da entrevista estivesse mais voltado para os processos de exclusão, os acadêmicos indígenas, que na sua grande maioria já atuam como professores em suas comunidades, subverteram o roteiro e falaram recorrentemente de seu compromisso com suas comunidades, da importância da escola para o seu povo, de ter professores indígenas nas escolas de suas comunidades, de ter uma educação escolar voltada para os interesses de suas comunidades.

* Universidade Católica Dom Bosco (UCDB), Campo Grande, MS, Brasil.
} 
qual finalidade tem sido intensa, procurando romper com a as marcas da matriz colonial e ressignificando radicalmente o significado da escola.

O artigo está estruturado em duas partes. Na primeira parte, trazemos os diferentes momentos da escolarização indígena e a luta dos povos indígenas, que culmina com o reconhecimento ao direito de uma escola indígena, intercultural, específica e diferenciada. Mostra-se que essa luta continua, pois o fim do colonialismo não significou o fim da colonialidade. Na segunda parte, trazemos as falas de acadêmicos indígenas, articulando-as com teóricos da interculturalidade e da escola indígena.

\section{Da escola colonial à escola indígena intercultural}

Os povos indígenas, desde o período da colonização, vêm lutando de múltiplas formas em defesa de suas identidades. Na produção das identidades indígenas, depois da invasão europeia, a escola tem tido um papel central - num primeiro momento, imposta pelo colonizador com o intuito de eliminar essas identidades e, atualmente, protagonizada pelos indígenas, com o objetivo de fortalecê-las.

Com base em Candau e Russo (2010), podemos dizer que há quatro momentos distintos da educação escolar indígena no Brasil. $\mathrm{O}$ primeiro inicia-se no período colonial e vai até as primeiras décadas do século XX; caracteriza-se pela "[...] violência etnocêntrica explícita de imposição da cultura hegemônica sobre as populações indígenas" (CANDAU; RUSSO, 2010, p. 155), ou seja, a escola servia para eliminar o indígena, sua cultura, sua língua. O segundo momento, das primeiras décadas do século XX até a década de 1970, caracteriza-se pela assimilação cultural, com o intuito de construir um Estado homogêneo. Nessa perspectiva, o indígena deveria ser assimilado pela cultura nacional para fazer parte da massa trabalhadora, pois o país estava se inserindo no modelo urbano/industrial. Nesse período, começam a surgir escolas bilíngues, mas quase sempre a língua materna era vista como elemento de transição para facilitar a assimilação cultural. O terceiro momento, nas décadas de 1970 e 1980, caracteriza-se pela emergência de experiências alternativas ligadas a lideranças comunitárias e à Igreja Católica Progressista, preocupadas em fortalecer a cultura e a identidade indígena. $\mathrm{O}$ quarto momento inicia-se no final dos anos 1980 e continua vigente; caracteriza-se pela defesa de uma escola intercultural, bilíngue e diferenciada, propondo um diálogo entre as culturas. Desse momento, a Constituição de 1988 é apontada tanto pelos povos indígenas quanto pelos pesquisadores desse campo como um marco decisivo para o direito a uma educação específica, diferenciada, incluindo o ensino na língua materna e os processos próprios de aprendizagem. Ressalte-se que se tratou não de uma dádiva do Estado brasileiro, mas de uma conquista, fruto do movimento indígena. Com essa Constituição e o aparato legal que vem sendo conquistado, abrem-se novas possibilidades, voltadas para as cosmologias de cada povo, assim contribuindo para o processo de afirmação identitária.

Cabe destacar que, apesar de todos os mecanismos de controle, das estratégias de assimilação e da violência empreendida pelo Estado Brasileiro para "ajudá-los" a "integrarse" à sociedade nacional, "[...] os índios que 'sobreviveram' o fizeram exatamente por terem mantido a sua diferença cultural e não terem se diluído no caldeirão da sociedade nacional" (CAMARGO; ALBUQUERQUE, 2003, p. 343).

A escola - inicialmente, uma imposição do colonizador aos povos indígenas e, como tal, a serviço dos interesses do projeto colonizador - pode ser vista como uma das instituições centrais para a assimilação das culturas indígenas, sendo marcada, portanto, por práticas sistemáticas de negação de suas identidades, com destaque para a proibição da língua materna. No entanto, graças à força, à luta e ao protagonismo dos povos indígenas, passou a ser um espaço/tempo de outros modos de estar nela, outros modos de educar nela, outros modos de relacionar-se com ela, outros modos de lidar com os saberes, outros modos de lidar com as epistemologias, outros modos de produzir identidades. Entender como se deu esse processo passa pelo reconhecimento do inesgotável poder de ressignificação e criação de homens e mulheres: "observando atentamente a vida na aldeia e as atividades desenvolvidas na escola, aparece, aos poucos, a força criadora 
de outros modos do dizer e do fazer escolar" (BERGAMASCHI, 2007, p. 201).

Desse modo, podemos dizer que a escola indígena, específica, diferenciada e intercultural talvez seja a forma mais visível do potencial humano de transgredir, ressignificar, hibridizar práticas, instituições e formas de saber/poder, pois a escola ocidental, autoritária, assimilacionista, homogeneizante, foi ou está sendo transformada num espaço/tempo significativo para a afirmação das etnias indígenas. Não se pode deixar de reconhecer a importância e o tamanho dessa conquista, ainda mais quando consideramos o contexto extremamente adverso em que ela se deu.

O processo colonizador, como argumenta Walsh (2010), foi implementado com a intenção de subordinar todas as diferenças culturais. Nele, não havia espaço para outras racionalidades, outras epistemologias, outros modos de ser, saber e viver. Esse processo, longe de acabar no fim do período colonial, continua marcando nosso modo de pensar e produzir conhecimento, isto é, o fim do colonialismo não significou o fim da imposição dos valores ocidentais aos povos indígenas, nem o fim da imposição de seus valores a todos e a todas que não os compartilham, produzindo "[...] traumas sobre traumas, violências sobre violências, negação sobre negação do outro" (SKLIAR, 2003, p. 111).

O processo posterior ao período colonial tem sido denominado de colonialidade e perdura no século XXI: "a colonialidade do poder [...] esteve e está de todo modo ativa, pois faz parte do contexto global dentro do qual ocorrem os processos que afetam todos os espaços concretos de dominação" (QUIJANO, 2002, p. 13). Mais especificamente, continuamos vivendo em espaços/tempos de colonialidade do ser, do saber, do poder e da cosmovisão. Se, durante muito tempo, os parâmetros eram eurocêntricos, Walsh (2010) argumenta que atualmente se trata de uma imposição "euro-usa-cêntrica", com características que lembram o projeto colonial, ou seja, a diferença continua sendo vista como algo a ser eliminado, corrigido, assimilado ou ignorado.

Para questionar, subverter e deslocar a colonialidade, com base em Walsh (2010), podemos dizer que é importante atuar em três dimensões: intercultural, interepistêmica e decolonial. Essas três dimensões, a rigor, mes- clam-se, encontram-se, entrecruzam-se, enfim, estão articuladas. Pensar na articulação dessas dimensões tem " [...] a grande vantagem de nos possibilitar pensar como práticas específicas (articuladas em torno de contradições que não surgem da mesma forma, no momento e no mesmo ponto) podem, todavia, ser pensadas conjuntamente" (HALL, 2003, p. 152).

Em relação à dimensão intercultural, cabe salientar que, conforme apontam Candau e Russo (2010), há um consenso, na produção bibliográfica e entre os pesquisadores do campo da interculturalidade, de que esse termo surgiu na América Latina com a educação escolar indígena. Ela é vista como um componente "[...] ético e político orientado à construção de democracias em que redistribuição e reconhecimento cultural sejam assumidos como imprescindíveis para a realização da justiça social" (CANDAU; RUSSO, 2010, p. 164). Com a dimensão intercultural, aprendemos, sobretudo com os indígenas e demais povos subalternizados, a questionar o Estado-Nação e a ideia de cultura nacional, não apenas com o intuito de incluir marginalmente a cultura indígena e afro-brasileira, mas colocando-as como constitutivas, como centrais, criando novas condições de pensar, conhecer, ser, estar e conviver. Os indígenas sistematicamente estimulam-nos a refletir "[...] sobre outros tempos e espaços, sobre o que significa viver, sobre como é possível construir outras narrativas identitárias. Instigam-nos também a pensar em como resistir, subverter, ressignificar práticas de colonização e de subordinação" (BACKES; NASCIMENTO, 2011, p. 26).

Quanto à dimensão interepistêmica, ela nos provoca a desenvolver esforços para transgredir os marcos epistemológicos eurousa-cêntricos que ainda caracterizam nossos modos de pensar e produzir conhecimentos, bem como nossas universidades. Para produzir epistemologias que não sejam a expressão de uma única lógica, notadamente da lógica da dominação e da exclusão da diferença, é fundamental incorporar os saberes dos movimentos sociais, com destaque para os indígenas, atentando para a pluralidade de conhecimentos, lógicas e racionalidades subjugadas e negadas, num esforço político-intelectual para criar relações, articulações e convergências entre eles (WALSH, 2010). 
Por fim, em relação à dimensão decolonial, é crucial mostrar que, tanto no passado quanto no presente, houve/há um esforço para desafiar a matriz colonial de poder e de dominação. Nesse sentido, é preciso mostrar que: a) as identidades sociais brancas, masculinas e heterossexuais, apesar de continuarem hegemônicas, sempre foram contestadas e subvertidas e que há inúmeras outras identidades, igualmente legítimas; b) apesar de toda violência física e simbólica empreendida para desumanizar os indígenas e negros, se multiplicam os modos de ser e existir humanamente; c) apesar da imposição da epistemologia ocidental moderna positivista como a única válida, há uma pluralidade epistêmica que, embora não seja reconhecida pela epistemologia universalizante e totalitária, responde melhor aos desafios desses povos; e) apesar dos mecanismos de controle e da negação histórica e sistemática das bases ancestrais espirituais dos povos indígenas, elas continuam presentes, mostrando outras possibilidades de estabelecer relações com a natureza e de dar sentido ao mundo. De modo sintético, como aponta Walsh (2010), desafiar a matriz colonial de poder e dominação, promovendo a decolonização, implica questionar a superioridade da identidade branca, masculina e heterossexual, sua superioridade ontológicoexistencial, sua superioridade epistemológica e sua superioridade cosmológica.

Como já apontamos, essas dimensões articulam-se. Portanto podem combinar-se de múltiplas formas, contribuindo para a decolonização, a produção de um pensamento outro e o fortalecimento de uma educação intercultural crítica (WALSH, 2009).

A seguir, argumentamos que os indígenas continuam mostrando que outras formas de poder, conhecer, ser e viver são possíveis. Eles continuam, no contexto atual, desfiando e subvertendo a matriz colonial e o fazem, em grande parte, pela ressignificação radical de uma instituição: a escola, mais especificamente, a escola intercultural, específica e diferenciada.

Para construir nossa argumentação, poderíamos recorrer à nossa convivência de mais de oito anos com alunos indígenas stricto sensu, mostrando o quanto eles possuem uma preocupação com a escola indígena, o quanto hibridizam os conhecimentos, o quanto mostram sistematicamente seus laços coletivos, o quanto afirmam suas identidades e sua cultura, o quanto não se dobram à matriz colonial. Poderíamos, ainda, recorrer às inúmeras dissertações defendidas pelos alunos indígenas, todas voltadas para a educação indígena, com preocupação com a interculturalidade, com a valorização de sua cultura e língua. Todos esses caminhos seriam promissores, mas neste artigo optamos por construir nossos argumentos tendo como base alunos indígenas de licenciaturas, cujas falas foram construídas em entrevistas semiestruturadas.

Foram entrevistados seis acadêmicos indígenas de diferentes licenciaturas e etnias presentes no Estado de Mato Grosso do Sul que estudam numa instituição de educação superior particular. A fim de manter o anonimato garantido quando da realização das entrevistas, nomearemos os indígenas apenas por letras e não forneceremos nenhum elemento de identificação.

A escolha de acadêmicos indígenas da graduação, segundo nosso entendimento, contribui para mostrar o quanto a preocupação com a escola intercultural, específica e diferenciada é uma preocupação dos povos indígenas e faz parte das reflexões de suas comunidades. Não é produto da interferência de educadores/pesquisadores de fora, como o artigo poderia dar a entender se fosse baseado na experiência stricto sensu e nas dissertações produzidas por indígenas, já que elas se dão num contexto de uma Linha de Pesquisa que tem como foco a educação indígena e a diversidade cultural.

\section{A desconstrução da matriz colonial por meio da escola indígena}

Como já destacado neste artigo, no contexto atual, a escola indígena, porque protagonizada pelos próprios indígenas, tem tido um papel relevante para a desconstrução da matriz colonial. Se considerarmos, como aponta Walsh (2010), que essa matriz colonial se funda, entre outras coisas, na suposta superioridade do poder, ser, conhecer e viver ocidental, podemos inferir que a forma mais concreta pela qual a escola indígena subverte a matriz colonial é a da afirmação da identidade étnica. Uma identidade étnica vista pelos próprios indígenas não como fixa e essencial, mas como o resultado das relações sociais e 
culturais, incluindo as relações com os não indígenas, como resultado de sua cosmologia, igualmente dinâmica: "a cosmologia dos povos indígenas não é estática, tampouco essencialista e pura, pois, como todas as sociedades, [...] também se modificam, se reinventam a todo o momento e saberão se reinventar diante de novos acontecimentos, entre eles, a escola" (BERGAMASCHI, 2007, p. 201). Nesse processo de afirmação, a língua materna assume um papel central, juntamente com a valorização dos conhecimentos tradicionais e dos processos próprios de aprendizagem e suas cosmologias.

Nesse sentido, queremos salientar o quanto os indígenas estão umbilicalmente comprometidos com essa escola, bem como o quanto lutam para que ela se distancie cada vez mais dos resquícios da escola colonial. $\mathrm{Na}$ pesquisa realizada com acadêmicos indígenas de diferentes etnias e diferentes licenciaturas, todos os entrevistados manifestaram essa preocupação. Eles procuram a formação superior, saindo de suas comunidades, com o firme compromisso de permanecerem nelas para poder oferecer uma educação intercultural.

Essa educação intercultural é produzida pelos próprios indígenas, pois, a rigor, os conhecimentos de formação que circulam nos cursos que frequentam são ocidentais, mas os indígenas os colocam em diálogo com os conhecimentos tradicionais, ressignificandoos de modo a se tornarem conhecimentos a favor da identidade indígena. É “[...] a cultura indígena interagindo com a sociedade não indígena" (Acadêmico A). Essa interação se dá sem perder de vista a preocupação com a comunidade, com a cultura: "o que é ensinado nas escolas do Brasil inteiro, a gente pega o que é bom para os índios e também trabalha a questão da cultura terena, os jogos terena, atividade da mulher terena, do homem terena" (Acadêmico B).

Na entrevista, esse acadêmico indígena do curso de Educação Física disse que o curso ensina a competição, mas que essa competição não faz parte de sua cultura: "na escola indígena, não percebo competição. [...] Eu tenho trabalhado muito com jogos cooperativos, não só com meninos, mas misturo. [...] Trabalho através de jogos cooperativos para evitar a competição" (Acadêmico B). Ele problematiza essa competição e mostra que, para seu povo, o importante é desenvolver atividades físicas que eduquem para a colaboração e cooperação. Esses jogos contribuem para o fortalecimento dos laços coletivos, dos vínculos comunitários. Diferentemente da Educação Física das escolas não indígenas, que exclui os alunos menos habilidosos, ele propõe jogos nos quais todos podem participar: "os que não praticam esporte, os menos habilidosos, a gente procura incluir nos jogos" (Acadêmico B).

$O$ acadêmico $B$ também questiona a Provinha Brasil, por basear-se somente nos conhecimentos gerais, ignorando os conhecimentos indígenas, o que contribui para criar uma imagem negativa na escola indígena: "eu sou contra a Provinha Brasil, que avalia o conhecimento das escolas no Brasil. [...] Nossa escola está abaixo da média, está muito fora do padrão, como eles dizem. Só que eles não viram que a educação que é trabalhada lá na escola é diferenciada".

$A$ acadêmica $C$ também questiona a ingerência indevida do Estado por meio de diretrizes que, muitas vezes, ainda carregam as marcas da colonialidade. Ela mostra como a comunidade questiona essas diretrizes e as subverte quando vão contra os interesses dos alunos indígenas: "quando uma diretriz está acima dos alunos, não é da realidade deles, ela não serve. A comunidade, a escola, a comunidade está atenta a isso".

Esses acadêmicos, vindo ao encontro do que os autores apontam (CANDAU; RUSSO, 2010; CANDAU, 2011; 2012; WALSH, 2009; 2010; BERGAMASCHI, 2007; BACKES; NASCIMENTO, 2011), estão sempre preocupados com o diálogo entre as culturas, com uma educação intercultural: "a escola precisa elaborar planos de trabalho para atender seus alunos em suas diferenças; dentro dessas diferenças, buscando igualdade" (Acadêmica C); "na escola indígena, temos que trabalhar o conhecimento tradicional e o conhecimento urbano, global" (Acadêmico B); "a escola pode trabalhar com várias culturas" (Acadêmico A); "a gente precisa conhecer a cultura deles, mas sem esquecer a cultura da gente, dos Terena" (Acadêmico F); "não deveria ter preconceito, porque cada um de nós é diferente. Caberia a cada um respeitar a cultura de cada um" (Acadêmico D); "nós estamos lutando para criar uma escola que respeite as culturas, que respeite a cultura 
indígena. Nós temos que tentar... Nós estamos conseguindo" (Acadêmico E).

É interessante observar como essas falas dos indígenas se referem a princípios que os autores da educação intercultural sistematicamente defendem. Candau (2011), ao discorrer sobre a diversidade cultural e a importância da educação intercultural, aponta: "as questões colocadas são múltiplas, visibilizadas principalmente pelos movimentos sociais, que denunciam injustiças, desigualdades e discriminações, reivindicando igualdade de acesso a bens e serviços e reconhecimento político e cultural" (CANDAU, 2011, p. 241). Candau (2011; 2012), em seus escritos, tem apontando sistematicamente a necessidade de combater os preconceitos e considerar as diferentes culturas. A autora questiona a hegemonia da cultura moderna, bem como a necessidade de articular a diferença com igualdade, tal como a acadêmica C apontou: "[...] dentro dessas diferenças, buscando igualdade". Para Candau (2012), a igualdade e a diferença, necessariamente, fazem parte de uma educação intercultural; elas não se opõem, elas fazem parte da mesma luta: "considero que hoje não é possível se trabalhar questões relacionadas à igualdade sem incluir a questão da diferença, nem se pode abordar a questão da diferença dissociada da afirmação da igualdade" (CANDAU, 2012, p. 239).

Candau (2012, p. 237) também argumenta que, para potencializar o processo de aprendizagem escolar, "[...] na perspectiva da garantia a todos/as do direito a educação, teremos de afirmar a urgência de se trabalhar as questões relativas ao reconhecimento e a valorização das diferenças culturais nos contextos escolares". Essa perspectiva é muito forte para os acadêmicos indígenas, que veem na presença de diferentes culturas uma possibilidade de diálogo que não gere preconceito, mas respeito.

Da mesma forma que é possível perceber a aproximação das reflexões dos acadêmicos indígenas com Candau (2011; 2012), essa aproximação também se dá em relação ao pensamento de Walsh (2009; 2010). Para a autora, assim como para Candau (2011; 2012), a educação intercultural deve ter uma preocupação constante para evitar “[...] a exclusão, negação e subalternização ontológica e epistêmico-cognitiva dos grupos e sujeitos racializados" (WALSH, 2009, p. 23). Ela argumenta, ainda, que a interculturalidade atualmente está presente em várias políticas de Estado na América Latina, mas muitas vezes acaba servindo aos interesses do próprio sistema de dominação, à colonialidade.

Nesse sentido, a autora argumenta em favor de uma interculturalidade crítica, preocupada sistematicamente em romper com as estruturas de discriminação, racismo e exclusão, de modo a contribuir para a educação de sujeitos capazes de conviver com a diferença cultural, rumo à construção de uma sociedade com justiça social e igualdade. Essa educação intercultural crítica, segundo Walsh (2009), não é algo pronto, mas um projeto a ser construído cotidianamente pelos grupos subalternizados, o que lembra a fala do acadêmico e quando diz que estão lutando por uma escola que respeite as diferenças e que estão conseguindo construí-la.

Podemos ainda afirmar que as falas dos acadêmicos indígenas entrevistados vêm ao encontro do que os pesquisadores que estudam as escolas indígenas têm apontado. Bergamaschi e Medeiros (2010, p. 61), no artigo em que descrevem a escola indígena Kaiagang, mostram o quanto a escola tem servido para que "[...] os povos indígenas possam lutar por seus direitos de forma mais simétrica, aprendendo o sistema de vida ocidental, mas mantendo e afirmando seus modos próprios de educação". Bergamaschi (2007, p. 211), referindo-se à escola indígena nas aldeias guarani, mostra como vai se diferenciando da escola ocidental pelos pequenos gestos cotidianos, "[...] sustentados pelas características de sua educação tradicional - a curiosidade, a observação, a imitação e o respeito, entre outros atributos responsáveis pela confecção da pessoa Guarani -, que se apropriam da escola, tornando-a sua". Gomes (2006, p. 325), estudando a escolarização entre os Xakriabá, mostra o quanto ela está profundamente ligada à forma como “[...] interpretam a própria experiência escolar e o sentido que atribuirão à escola no processo de afirmação da própria identidade e da busca de garantias ao direito à escola diferenciada". Camargo e Albuquerque (2003, p. 359), que analisaram o processo que está sendo travado pelos Xavante para tornar a escola indígena específica e diferenciada, apontam como algumas das dificuldades a "[...] existência de um RCNEI, as dificuldades em romper com 
os rígidos calendários do não-índio, com o material didático elaborado sob forte influência não índia".

Portanto observamos que há uma articulação entre as falas dos acadêmicos indígenas, pesquisadores da educação intercultural e pesquisadores da escola indígena, mas o protagonismo continua sendo dos povos indígenas. Eles estão permanentemente afirmando suas identidades e questionando a colonialidade.

\section{Considerações finais}

Ao finalizarmos este artigo, lembramos Bhabha (1998) quando argumenta como os saberes subalternizados se infiltram nos saberes hegemônicos e, nesse processo, acabam subvertendo a própria hegemonia e diminuindo sua força. Entendemos que isso tem sido feito de modo muito marcante pelos povos indígenas. Como aponta Bergamaschi (2007), um olhar atento mostra as especificidades de uma escola indígena e o quanto ela traz das marcas de sua cultura, da sua cosmovisão e de seus conhecimentos.
Nesse sentido, queremos reiterar algumas especificidades que nosso esforço para termos um olhar atento percebeu - um esforço sempre necessário, já que ainda estamos imersos na colonialidade, mesmo que procuremos combatê-la. Salientamos o questionamento da competição e a valorização da cooperação; o questionamento das diretrizes quando estas não servem aos interesses dos povos indígenas; a crítica à Provinha Brasil; a defesa da interação entre as culturas; a valorização do conhecimento tradicional, mas dialogando com o conhecimento global; e a importância de trabalhar várias culturas nas escolas.

Essas especificidades tornam-se mais significativas ao considerarmos, como procuramos fazer neste artigo, o processo histórico da relação da escola com os povos indígenas. Elas mostram a resistência, a luta, a força dos povos indígenas em defesa de seus saberes, modos de ser e viver, não se curvando à matriz colonial e apontando que conhecimentos outros são possíveis, modos outros de ser são possíveis, modos outros de interpretar o mundo são possíveis.

\section{Referências}

BACKES, José Licínio; NASCIMENTO, Adir Casaro. Aprender a ouvir as vozes dos que vivem nas fronteiras étnicoculturais e da exclusão: um exercício cotidiano e decolonial. Revista Série-Estudos, Campo Grande, n. 31, p. 25-34. 2011.

BERGAMASCHI, Maria Aparecida. Educação escolar indígena: um modo próprio de recriar a escola nas aldeias guarani. Cadernos Cedes, Campinas, v. 27, n. 72, p. 197-213, maio/ago. 2007.

BERGAMASCHI, Maria Aparecida; MEDEIROS, Juliana Schneider. História, memória e tradição escolar indígena: o caso de uma escola Kaingang. Revista Brasileira de História. São Paulo, v. 30, n. 60, p. 55-75. 2010.

BHABHA, Homi. O local da cultura. Belo Horizonte: UFMG, 1998.

CAMARGO, Dulce Maria Pompêo de; ALBUQUERQUE, Judite Gonçalves de. Projeto pedagógico xavante: tensões e rupturas na intensidade da construção curricular. Cadernos Cedes, Campinas, v. 23, n. 61, p. 338-366, dezembro, 2003.

CANDAU, Vera Maria Ferrão. Diferenças culturais, cotidiano escolar e práticas pedagógicas. Revista Currículo sem Fronteiras, v. 11, n. 2, p. 240-255, jul./dez. 2011.

CANDAU, Vera Maria Ferrão. Diferenças culturais, interculturalidade e educação em direitos humanos. Revista Educação e Sociedade, v. 33. n. 118, p. 235-250, jan./mar. 2012.

CANDAU, Vera Maria Ferrão; RUSSO, Kelly. Interculturalidade e educação na América Latina: uma educação plural, original e complexa. Revista Diálogo Educacional, v. 10, n. 29, p. 151-169, jan./abr. 2010.

GOMES, Ana Maria. O processo de escolarização entre os Xakriabá: explorando alternativas de análise na antropologia da educação. Revista Brasileira de Educação, v. 11, n. 32, maio/ago. 2006.

HALL, Stuart. Da diáspora: identidades e mediações culturais. Belo Horizonte: UFMG, 2003.

QUIJANO, Anibal. Colonialidade, poder, globalização e democracia. Revista Novos Rumos, v. 17, n. 37, p. 4-25, maio./ ago. 2002.

SKLIAR, Carlos. Pedagogia (improvável) da diferença: e se o outro não estivesse aí? Rio de Janeiro: DP\&A, 2003.

WALSH, Catherine. Estudios (inter)culturales en clave de-colonial. Revista Tábula Rasa, n. 12, p. 209-227, jan./jun. 2010.

WALSH, Catherine. Interculturalidade crítica e pedagogia decolonial: in-surgir, re-existir e re-viver. In. CANDAU, Vera Maria (Org.). Educação intercultural na América Latina: entre concepções, tensões e propostas. Rio de Janeiro: 7 Letras, 2009. p. 12-43. 